\title{
A LITERATURA INFANTIL E A LEITURA DO MUNDO NAS PONTAS DOS DEDOS
}

\author{
CHILDREN'S LITERATURE AND READING THE WORLD AT THE FINGER POINTS
}

\author{
Dagmar Mello Silva ${ }^{1}$ \\ Ana Cristina Teixeira Prado.
}

\section{http://dx.doi.org/10.52641/cadcaj.v7i1.512}

RESUMO: Este artigo resultou de uma pesquisa de Mestrado que investigou modos de promover acessibilidade, às imagens da Literatura Infantil, para crianças com deficiência visual. Portanto, trataremos adiante das questões teóricas, levantadas na referida pesquisa, sobre a importância da literatura infantil na formação humana, apresentando conteúdos para que professores e professoras possam compreender como essa literatura deveria ser apresentada para que crianças cegas e com baixa visão possam ler com autonomia, através das pontas de seus dedos. Em síntese, trata-se de uma exposição teórica fundamentada em dados empíricos, realizados por uma pesquisaintervenção, que procurou promover reflexões com professores e professoras sobre a importância de se produzir artesanalmente, a acessibilidade necessária e adequada à literatura, para ao público infantil com deficiência visual.

Palavras-Chave: Literatura Infantil. Formação Humana. Acessibilidade. Crianças. Deficiência Visual.

ABSTRACT: This article resulted from a Master's research that investigated ways to promote accessibility, to images from Children's Literature, for children with visual impairments. Therefore, we will expose theoretical questions raised in the referred research, about the importance of children's literature in human formation, presenting contents for teachers can understand how this literature should be presented for blind and low vision children can read independently, through your fingertips. In summary, this is a theoretical exposition based on empirical data with the aim was make teachers aware of the importance of producing, artfully, the necessary and adequate accessibility to literature, for children with visual impairments.

Keywords: Children's Literature. Human formation. Accessibility. Kids. Visual impairment.

\section{INTRODUÇÃO}

O contato da criança com a Literatura Infantil deve ser promovido, desde muito cedo, em favor do desenvolvimento linguístico, socioafetivo, cognitivo, da capacidade crítica e criativa, do olhar estético e do conhecimento de mundo. Se exposta a um ambiente propício, a criança começa a aprender o uso e as funções do livro como instrumento de comunicação. Ou seja, a criança adquire, assistematicamente, hábitos de leitura.

\footnotetext{
1 Professora Associada da Universidade Federal Fluminense. Orcid: 0000-0002-5863-3607. E-mail: dag.mello.silva@gmail.com.

${ }^{2}$ Mestre em Diversidade e Inclusão pela Universidade Federal Fluminense e professora da Secretaria Municipal de Educação de Niterói. Orcid: 0000-0002-6263-2199. E-mail: anactprado@gmail.com.
} 
Segundo Vygotsky (2007, p. 7), "[...] a experiência social exerce seu papel através do processo de imitação; quando a criança imita a forma pela qual o adulto usa instrumentos e manipula objetos, ela está dominando o verdadeiro princípio envolvido numa atividade particular." $\mathrm{Na}$ escola, espaço privilegiado de acesso à literatura, o professor é o mediador entre a criança e o livro e deve oportunizar atividades contextualizadas para despertar o hábito e o gosto pela leitura.

Contudo, esses mecanismos quase espontâneos de se relacionar com a obra de literatura infantil, não atendem às necessidades de aprendizagem de todas as crianças. Aquelas com deficiência visual, cegas e com baixa visão, que apresentam importante diminuição da acuidade do campo visual, geralmente, têm o primeiro contato com a cultura escrita na escola, posto que livros impressos em caracteres ampliados, cores contrastantes (claro-escuro) e escritos no sistema Braille, com ilustrações produzidas com estímulos multissensoriais, nem sempre fazem parte de seus cotidianos, como objeto cultural e socialmente estabelecido.

Como qualquer estudante em processo de alfabetização, o estudante com deficiência visual precisa do contato pleno com a literatura infantil: palavra e imagem. Os livros de histórias infantis despertam o gosto de ler e não têm propósito meramente pedagógico, divertem, incentivam a busca de novos livros e apoiam na consolidação da competência da leitura. Ler é um gosto que pode se formar desde a tenra idade. E quanto mais cedo, melhor, pois a literatura é arte e a arte produz tremores indispensáveis à formação humana.

Para permitir que os livros de Literatura Infantil, possam, tanto quanto possível, transmitir aos estudantes com deficiência visual, experiências estéticas, tal qual transmitem aos demais estudantes videntes, são necessárias algumas adaptações de acesso a palavra escrita no sistema Braille, em tipos ampliados e a confecção de imagens que valorizem os sentidos remanescentes desses estudantes através da exploração tátil, presença de cores vibrantes e contrastantes (claroescuro), aromas e sons característicos dos signos, aspectos não contemplados nas inúmeras publicações disponíveis no mercado editorial. Em nossa pesquisa de Mestrado ${ }^{3}$ nos preocupamos com esses cuidados e procuramos refletir, junto aos professores e professoras da Rede Municipal de Educação do Município de Niterói sobre a importância de se produzir artesanalmente, a acessibilidade necessária e adequada ao público infantil com deficiência visual. Deste modo, esse artigo, trata de questões teóricas levantadas na referida pesquisa, sobre a importância da Literatura Infantil na formação humana e traz conteúdos para que professores e professoras possam

\footnotetext{
${ }^{3}$ A pesquisa: "Entre linhas e imagen - A Produção de Literatura Infantil acessível aos estudantes com deficiência visual dos anos iniciais, por meio de um curso de Grafia Braille para professores - autoria de Ana Cristina Teixeira Prado, foi desenvolvida no Curso de Mestrado Profissional em Diversidade e Inclusão (CMPDI) da Universidade Federal Fluminense, orientada pela Prof. ${ }^{a}$ Dr $^{a}$ Dagmar de Mello e Silva, defendida e aprovada no ano de 2020. https://www.youtube.com/watch?v=Rux9iA40E7I\&t=6s
} 
compreender como essa literatura pode se disponibilizada para que crianças cegas e com baixa visão possam ler com autonomia, através das pontas de seus dedos.

\section{CONSIDERAÇÕES HISTÓRICAS E ESTÉTICAS SOBRE A LITERATURA INFANTIL}

A história da literatura infantil toma impulso no século XVII, quando narrativas populares, contadas para e por adultos, começaram a ser adaptadas para o público infantil, com o propósito moral. Porém, a popularização desse gênero literário está intimamente ligada ao surgimento da escola Moderna. Antes dessa época, não havia livros endereçados às crianças que, até então, eram vistas como adultos em miniatura. Os primeiros livros infantis foram escritos por pedagogos e professores com o objetivo de estabelecer padrões comportamentais exigidos pela sociedade burguesa que se estabelecia como classe social dominante, sem se preocupar com os anseios próprios da infância. Ou melhor, nos primeiros tempos, o livro infantil era eminentemente moralista, didático e sua leitura utilitária, de valor formativo. Não se escrevia, portanto, para as crianças. Segundo Zilberman (2003, p.13):

[...] a concepção de uma faixa etária diferenciada, com interesses próprios e necessitando de uma formação específica, só acontece em meio à Idade Moderna. Esta mudança se deveu a outro acontecimento da época: a emergência de uma nova noção de família, centrada não mais em amplas relações de parentesco, mas num núcleo unicelular, preocupado em manter sua privacidade (impedindo a intervenção dos parentes em seus negócios internos) e estimular o afeto entre seus membros.

Com a Idade Moderna, a concepção de família, tal qual a de infância, começa a se modificar. A criança passa a ser considerada como alguém que vive um tempo específico da vida, com necessidades e características próprias, devendo receber uma educação específica. Diante dessas mudanças sociais, surge a necessidade de se pensar uma literatura voltada para a infância.

Charles Perrault (1628-1703), nobre francês, coletou e adaptou narrativas folclóricas, antes contadas apenas nos salões parisienses. Em meio a profundas transformações sociais, em 1697, Perrault editou os "Contos de Mamãe Gansa", originalmente intitulados como "Histórias ou contos do tempo passado com moralidades". Dentre os contos compilados, estão: “Chapeuzinho Vermelho", “A Bela Adormecida”, “O Barba Azul”, "O Gato de Botas”, “As Fadas", "Cinderela”, “Henrique”, o Topetudo" e “O Pequeno Polegar”. Eram adaptações pedagógicas, com "[...] caráter de advertência, fazendo com que a personagem que se afastasse das regras estabelecidas seja punida, como no conto "Chapeuzinho Vermelho" (CADEMARTORI, 2010, p. 29). Charles Perrault estabeleceu as bases para um novo gênero literário: os contos maravilhosos ou contos de fadas que, por muito tempo, permaneceram como paradigmas da Literatura Infantil. 
No início do século XIX, na Alemanha, com o surgimento do nacionalismo romântico e a valorização da cultura popular, os irmãos Grimm, Jacob (1785-1863) e Wilhelm (1786-1859), estudiosos da língua e da história do povo alemão, recolheram e adaptaram contos populares, como "João e Maria" e "Rapunzel" e deram uma nova versão literária a outros, como "Chapeuzinho Vermelho", ampliando a coleção dos contos de fadas.

O dinamarquês Hans Christian Andersen (1805-1875), transformou narrativas da tradição oral em histórias fantásticas ou com elementos da natureza, como "O Patinho Feio", "A Roupa Nova do Rei”, "A Pequena Sereia" e "A Pequena Vendedora de Fósforos". Devido à relevância de sua contribuição para o mundo da literatura infanto-juvenil, comemora-se no dia 2 de abril, data de seu nascimento, o Dia Internacional do Livro Infanto-juvenil e, desde 1956, o Prêmio Hans Christian Andersen, o mais importante desse gênero literário, recebeu o seu nome. Outros escritores, não menos importantes, contribuíram para a constituição dos padrões literários do texto infantil: o italiano Carlo Collodi (1826-1890), com "Pinóquio"; o inglês Lewis Carroll (1832-1898), autor de "Alice no País das Maravilhas"; o norte-americano Lyman Frank Baum (1856-1919), em “O Mágico de Oz".

A história da Literatura Infantil brasileira inaugurou-se quase no século XX, embora apareçam, ao longo do século XIX, publicações esporádicas destinadas às crianças. A fantasia nacional surgiu com a chegada da Primeira República (1889-1930), a partir das mudanças sociais, principalmente, com a ascensão da classe média urbana. Carl Jansen (1829-1889), escritor, tradutor, jornalista e professor, traduziu e adaptou clássicos europeus como “As Mil e Uma Noites”, "Dom Quixote de La Mancha”, "Robinson Crusoé” e vários contos dos Irmãos Grimm. E ainda, Figueiredo Pimentel (1869-1914), contista, cronista, diplomata, jornalista, poeta e romancista, publicou os "Contos da Carochinha", obra que reúne os contos de Charles Perrault, Irmãos Grimm, Hans Christian Andersen.

$\mathrm{Na}$ virada do século, a produção literária no Brasil continuou sendo, em sua maioria, de traduções e adaptações de livros estrangeiros, mas já havia uma preocupação em promover uma literatura nacionalista e educativa, representativa da realidade nacional. Lajolo e Zilberman (1994, p.88) explicam:

[...] surgem as obras nacionais, patrióticas de Olavo Bilac, em parceria, ora com Coelho Neto, ora com Manuel Bonfim, seguindo-se Júlia Lopes de Almeida e Tales de Andrade, inspiradas em obras europeias, que sucederam a traduções-adaptações, mas com um caráter de nacionalização. A produção literária, nessa época, é marcada por preocupação moralista, exaltação do trabalho, disciplina, obediência e, acima de tudo, um cantar à beleza da pátria.

Mas, foi a obra de Monteiro Lobato (1882-1948), genuinamente brasileira, que revolucionou a literatura infantil nacional. Cunha (1991, p. 24) afirma: "Com Monteiro Lobato é 
que tem início a verdadeira literatura infantil brasileira". Os textos de Lobato relacionam realidade e fantasia e valorizam o universo brasileiro. Porém, há que se ressaltar os conteúdos maniqueístas e estereótipos racistas presentes em suas obras, como, em "Caçadas de Pedrinho” (1933), na qual faz referências racistas à personagem negra - Tia Nastácia. Referências como estas vêm provocando muitas polêmicas e críticas à obra infantil de Monteiro Lobato, nos dias atuais, mas não há como, simplesmente, apagá-lo da história da literatura infanto-juvenil, pois não podemos negar que o “Sítio do Picapau Amarelo", escrito entre 1920 e 1947, se tornou símbolo da literatura infantil brasileira e alimentou o imaginário de muitas gerações, por meio de um mundo povoado por personagens que encantaram as crianças que fomos um dia. Lobato habita um lugar especial na memória dos tempos de criança de muitos adultos de hoje, mesmo que, nos dias atuais, tenhamos a obrigação política de problematizar os conteúdos racistas de suas obras, já que defendemos uma sociedade inclusiva.

Com o fortalecimento do mercado literário infantil no Brasil, escritores contemporâneos, consagrados pelo público adulto, também publicaram livros infantis: Érico Veríssimo, Clarice Lispector, Cecília Meireles, Jorge Amado, Vinicius de Moraes, Ferreira Gullar e muitos outros. Nos anos 1970, com as demandas escolares, há uma expansão do mercado consumidor de livros infantis, utilizados como apoio à prática pedagógica. A produção literária, dessa década, apresenta elementos de denúncia e crítica social, ironia, belas ilustrações, linguagem coloquial e inovadora representada pelas publicações de Ana Maria Machado, Ruth Rocha, Lygia Bojunga Nunes, Pedro Bandeira, Ziraldo, entre outros.

A literatura infantil se distingue das demais por ter um público recortado, bem definido, com linguagem própria, com uma intencionalidade de escrita para se comunicar com seus leitores. Logo, o conceito de Literatura Infantil vincula-se ao de infância, entendendo a criança como um sujeito histórico, inserido em um contexto social. A definição de Literatura Infantil concilia aspectos estéticos e pedagógicos, enquanto arte, move o pensamento criativo e imaginativo. Nas palavras de Coelho (2000, p.9) "Literatura infantil é, antes de tudo, literatura; ou melhor, a arte: fenômeno de criatividade que representa o mundo, o homem, a vida, através da palavra. Funde os sonhos e a vida prática, o imaginário e o real, os ideais e sua possível/impossível realização...".

$\mathrm{Na}$ educação, a Literatura Infantil ocupa lugar de destaque, pois contribui para o desenvolvimento e aprendizado do ser humano, já que "[...] ler não é apenas decodificar, é compreender e, mais ainda, é indagar, deduzir, inferir, associar, intuir, prever, concluir, discordar, concordar, acrescentar, selecionar, entre outras formas de interpretar e fruir um texto [...]" (CORRÊA, 2003, p. 53). Porém, há que se atentar, que por estar dirigido às crianças, esse gênero literário, muitas vezes, assume um caráter meramente instrumental e pedagógico, distanciando-se 
da função primordial que seria permitir que cada um responda melhor à sua vocação de ser humano, ampliar nossa própria humanidade, pois "a realidade que a literatura aspira compreender é, simplesmente [...] a experiência humana" (TODOROV, 2009, p. 76).

Nessa perspectiva, a literatura voltada para a infância, deve assumir a função antes destinada à literatura para o público adulto, se apresentando como "porta de entrada" das crianças, para o mundo da cultura escrita. Livros, histórias, poemas, imagens vão colocando as crianças diante de outras formas de dizer o mundo, ampliam suas referências, dilatam também seus olhares sobre si mesmas e sobre o outro.

\subsection{A IMPORTÂNCIA DA LITERATURA INFANTIL NA FORMAÇÃO DO LEITOR}

O aprendizado da língua oral precede o da língua escrita, pois a criança lê o mundo por meio da oralidade, muito antes de saber ler e escrever. A língua, instrumento de comunicação e expressão, também é brinquedo, possibilidade de descoberta do mundo. Para Benjamin (2013, p. 72), a linguagem não "é somente comunicação do comunicável, mas é, ao mesmo tempo símbolo do não comunicável". O autor faz uma distinção entre língua e linguagem. É a partir de linguagem que o mundo nos é apresentado, mas é pela língua que podemos expressar as ideias que fazemos do mundo. É a palavra que torna nossos pensamentos e ideias comunicáveis. "Isso significa que a língua [...], não é, em absoluto, a expressão de tudo o que podemos - supostamente expressar através dela, mas, sim, a expressão imediata daquilo que se comunica dentro dela" (BENJAMIN, 2013, p. 51). Nas mãos da criança, os livros de histórias infantis assumem um caráter que está além daquilo que eles comunicam em palavras, mesmo que a língua esteja presente, comunicando em suas páginas, pelas palavras, aquilo que o autor quis expressar, não é esse aspecto imediato da comunicação que importa, mas, sim, o que a criança captura da linguagem e transforma.

A literatura não deve ser vista como um meio, mas como um fim em si mesma. Ela permite o desenvolvimento do olhar estético e a apreciação da arte. Abramovich (1997, p.16) afirma que escutar histórias "[...] é o início da aprendizagem para ser um leitor, e ser leitor é ter um caminho absolutamente infinito de descoberta e de compreensão do mundo". Escutar histórias é entregarse, envolver-se na trama, tornar-se protagonista, invadir a cena, modificar o cenário, ressignificar os acontecimentos e deixar brotar emoções diversas. Quando a criança se envolve no mundo ficcional, assume a condição de participante ativo, desenvolvendo a imaginação, emoções e sentimentos de forma prazerosa e significativa. A literatura apresenta elementos para elaborar o real no qual se insere e refazê-lo, relacionando e harmonizando fantasia e realidade. Ouvir histórias 
"é uma possibilidade de descobrir o mundo imenso dos conflitos, dos impasses, das soluções que todos vivemos [...] e, assim, esclarecer melhor as próprias dificuldades ou encontrar um caminho para a resolução delas..." (ABRAMOVICH, 1997, p. 18).

A literatura interroga a realidade e permite à criança perceber e compreender essa realidade. Por meio do livro, a criança se transforma porque pode "[...] imaginar o que não viu, o que não vivenciou" (VYGOTSKY, 2009, p. 25). Quem lê um livro pode estabelecer experiências a partir dos seus conhecimentos, da sua sensibilidade e do contexto em que ambos se inserem, tornando insubstituível o prazer desse contato, visto que o texto é repleto de possibilidades estéticas que não se encerram entre o leitor e a palavra.

Antes de ensinar a ler, é preciso despertar o gosto e o prazer pela leitura. O interesse pela leitura é o ponto de partida para a formação do leitor. É preciso deixar ao alcance das mãos e dos olhos da criança um acervo diversificado, atualizado e instigante. Livros coloridos, com diferentes formas e tamanhos para que possa explorá-los: folheá-los, cheirá-los, tocá-los, identificar cores e formas, contemplar as imagens e contar histórias, mesmo sem saber ler. A experiência da leitura precisa ser um momento compartilhado, prazeroso e lúdico.

É no ambiente escolar que grande parte das crianças tem o primeiro contato com a literatura. Motivo pelo qual a Literatura Infantil tornou-se inseparável da educação. Por conseguinte, não se deve tratar a leitura apenas como obrigação escolar. A importância do contato da criança com a literatura, situa-se muito além da alfabetização. Muitas vezes, por estar dirigida às crianças, a Literatura Infantil assume um compromisso com os ensinamentos formais, afastandose da sua função essencial: humanizar. A literatura, segundo Candido (2011, p. 122), "nos organiza, nos liberta do caos e, portanto, nos humaniza", pois "a literatura confirma e nega, propõe e denuncia, apoia e combate, fornecendo a possibilidade de vivermos dialeticamente os problemas" (CANDIDO, 2011, p. 133). Ler é criar consciência de si, é examinar o mundo em que se vive para transformá-lo.

\section{ALFABETIZAÇÃO E LITERATURA INFANTIL}

A leitura e a escrita, conteúdo central da escola dos anos iniciais do Ensino Fundamental, têm a função de incorporar a criança à cultura do grupo em que vive. O contato estabelecido entre a criança e a literatura, mediado pelo professor, oportuniza a experimentação da potencialidade linguística, decifrando os segredos do mundo que a cerca e do mundo da imaginação, podendo convencê-la do quão prazeroso é o processo de aprendizado da leitura e da escrita à medida que começa a combinar e permutar letras, atentando para os movimentos delas e os resultados dessa 
movimentação. Ler é construção de sentidos com a língua, motivado por um entusiasmo contínuo, pelo prazer da descoberta, pelo desejo de se transformar em leitor e inserir-se na sociedade. Como assegura Freire (2006, p. 11), "a compreensão do texto a ser alcançada por sua leitura crítica implica a percepção das relações entre texto e contexto." Nessa direção, ler humaniza, liberta e socializa.

De acordo com Soares (2003), é essencial entender a aprendizagem da leitura e da escrita como um processo ativo, que se dá por duas vias: a alfabetização, "tecnologia" do ler e escrever; e o letramento, uso dessa "tecnologia" para uma participação efetiva e competente em práticas sociais que envolvem a leitura e a escrita. Letrar vai muito além de alfabetizar, já que implica na inclusão da criança no mundo da escrita, ampliando sua inserção política e participação social. Essas duas aprendizagens são distintas, mas inseparáveis, ou seja, é imprescindível alfabetizar letrando.

Considera-se, então, a literatura infantil, uma valiosa aliada do processo de alfabetização, tendo em vista a possível construção de uma relação lúdica entre o mundo da imaginação, dos símbolos subjetivos e dos signos da cultura escrita. A conexão entre alfabetização e Literatura Infantil deve ser pensada como algo amplo e abrangente, já que nessa afinidade, ambas são modificadas e reinventadas.

\section{FUNÇÃO E IMPORTÂNCIA DAS IMAGENS NA LITERATURA INFANTIL}

As imagens não servem apenas para dar cor e forma ao texto verbal, elas agregam-lhes sentidos, posto que as imagens comunicam aspectos semióticos que precisam ser transmitidos, também, para o leitor com deficiência visual. As ilustrações dos livros de histórias infanto-juvenis constituem mais uma entre as tantas multimodalidades de formas e estéticas dos textos que circulam em nossos dias. Portanto a acessibilidade às ilustrações dos livros, para crianças cegas ou com baixa visão, não se restringe a uma questão estética somente, mas à possibilidade de atender uma educação atenta a importância de promover multiletramentos no contexto de uma sociedade em que as imagens constroem narrativas. Pode-se afirmar, portanto, que longe de configurarem objeto de contemplação passiva, as imagens requerem do leitor uma postura crítica e investigadora. Não basta descrever as imagens. Isso não atende às suas possibilidades de fruição. A leitura das imagens requer experiência, sentimentos e capacidade de ver o visível e o invisível, visto que nenhuma imagem nos é dada em absoluto.

Imagens e palavras se entrelaçam na narrativa infantil, despertam a imaginação, afloram sensações, sentimentos e possibilitam a construção de sentidos. A visão de imagem afasta-se da ideia de adorno e aproxima-se da perspectiva de algo que comunica um conteúdo que acompanha de modo complementar ou suplementar o texto verbal. 
As imagens, muito além de conquistarem a atenção do leitor, apoiam na tradução do sentido do texto, pois a leitura é um jogo de apropriações. Maia (2002, p. 3), a esse respeito, argumenta que "a ilustração não representa, quando muito, apresenta: a ilustração inventa!" Ou seja, a ilustração dilata as possibilidades interpretativas do texto.

Maia (2002, p. 3) defende que a imagem cria "[...] na obra um outro texto que se abre ao olhar. " Isso porque ler um livro não é só interpretar palavras, mas também, imagens. É evidente que o texto verbal e a imagem são fontes de informação distintas. Como sugere Leffa (1996), ler é extrair sentido do texto (a imagem também é texto). Para tanto, é fundamental que, desde bem cedo, a criança possa estabelecer relações de sentido com o texto verbal e visual da obra literária infantil, por meio de um olhar sensível e atento.

\section{DEFICIÊNCIA VISUAL: DESENVOLVIMENTO E APRENDIZADO}

A visão é um sentido muito importante para o aprendizado. É o sentido que mais informações provê sobre o ambiente. Por meio dele, adquire-se boa parte dos conhecimentos a respeito do mundo circundante. Por essa razão, a visão é o sentido "[...] mais explorado para as nossas aprendizagens, para as nossas buscas e formação de conceitos" (MOSQUERA et al., 2015, p. 56). As crianças aprendem, essencialmente, usando os cinco sentidos. Como pensar, então, o aprendizado dessas crianças, se nossos processos de ensino e de aprendizado se sustentam basicamente no aporte da visão?

Para Cardeal (2009, p. 18), "o desconforto do 'não-saber' é o que nos move em direção à tentativa de buscar compreender as implicações e complexidades do 'não-ver'." É preciso que o professor entenda como a deficiência visual interfere no desenvolvimento e no aprendizado com o fim de elaborar estratégias de ensino que satisfaçam as necessidades de aprendizagem dessas crianças, promovendo a sua plena e efetiva participação nas atividades.

A concepção sócia histórica do desenvolvimento humano, iniciada por Vygotsky, enfatiza os processos interativos na constituição do ser humano, evidenciando o papel da sociedade e da cultura no desenvolvimento. Vygotsky (2008) defende que para se desenvolver e construir conhecimento, o homem precisa do outro. A linguagem possibilita as relações interpessoais e permite ao indivíduo comunicar-se socialmente. $\mathrm{O}$ autor afirma que todas as operações mentais não poderiam se dar sem a linguagem, pois é ela que permite ao homem pensar em estruturas independentes que vão se constituindo simultaneamente. Enfatiza que a cultura se integra ao homem pela atividade cerebral, estimulada pela interação entre parceiros sociais e mediada pela linguagem. O pensador entende que as funções mentais superiores são socialmente formadas e culturalmente transmitidas por meio da linguagem. Mesmo que uma criança tenha potencial 
biológico para se desenvolver, se não interagir, não se desenvolverá como poderia. Na interação com os outros e consigo mesma, na internalização, a criança apreende conhecimentos, papéis sociais e valores por meio da linguagem. Nas palavras de Vygotsky (2008, p. 113): “A fala interior é a fala para si mesmo; a fala exterior é para os outros. [...]. Esta última consiste na tradução do pensamento em palavras, na sua materialização e objetificação. Com a fala interior, inverte-se o processo: a fala interioriza-se em pensamento".

Vygotsky (2012) evidencia que os danos no desenvolvimento e no aprendizado causados às crianças com deficiência sensorial não são condicionadores irremediáveis do desenvolvimento biológico e social. É certo que do ponto de vista biológico, a cegueira acarreta perdas importantes, considerando a realidade de uma sociedade que privilegia as informações visuais. Contrariamente do que se pensa no senso comum, para esse pesquisador o tato e a audição não "compensam" a falta da visão, posto que é a linguagem que assume o papel de aparato/sistema de compensação.

Também as emoções, os sentimentos, a fantasia, o pensamento e os demais processos da psique do cego estão subordinados à tendência comum a compensar a cegueira. A fonte da compensação da cegueira não é o desenvolvimento do tato ou a maior sutileza do ouvido, senão a linguagem, ou seja, a utilização da experiência social, a comunicação com os videntes (VYGOTSKY, 2012, p. 106-107) (tradução nossa).

Kastrup (2007), por sua vez, não considera que haja uma compensação, mas sim, "novos investimentos de atenção", visto que a ausência da visão não aguça outros canais sensoriais, mas implica numa atuação diferenciada dos mesmos, na percepção e compreensão das informações oferecidas pelo ambiente, graças à neuroplasticidade, capacidade do cérebro de estabelecer novas conexões e alterações nas suas estruturas e funções a partir das experiências, ações modeladoras das aprendizagens.

Por meio da linguagem, fonte principal de desenvolvimento e aprendizado comum à criança com ou sem deficiência visual, o adulto ajuda a criança a se relacionar com o mundo para conquistar o seu potencial. Para o autor, a linguagem é fundamental à formação de conceitos e a escola, espaço de aprendizado para todos, é indispensável para a sistematização dos conhecimentos, já que a mediação do professor tem intencionalidade educativa.

As crianças com deficiência visual necessitam de mais tempo para compreender o todo, formar a imagem, elaborar a noção de permanência e ausência do objeto e para instalar o comportamento de busca, fundamental na construção desses conceitos. As informações táteis e auditivas não bastam. Essas crianças precisam de vivências corporais contextualizadas e significativas para aperceberem-se de que o objeto ainda existe, mesmo quando já não mais está sob seu controle tátil. Para construir a noção do objeto, elas precisam agir sobre ele: manipulá-lo, nomeá-lo, dar-lhe função, experimentá-lo. $\mathrm{Na}$ falta da visão, o processo de ensino e de 
aprendizagem ocorrerá por meio da integração dos sentidos remanescentes, potencializando-se e expressando-se por meio da linguagem. Para as crianças cegas e com perda visual severa assimilarem as "coisas" do mundo, precisam estabelecer contato físico com os objetos e com as pessoas.

Diferentemente do sentido óptico da visão, que proporciona uma experiência sensorial global, o tato é analítico. Para os que têm visão, a imagem que veem é sempre totalizadora, instantânea, espacial e integradora. O reconhecimento tátil não funciona assim. É sequencial, estritamente temporal e, por conseguinte, mais lento (SACKS, 1995). Desse modo, para as crianças com ausência e importante perda visual compreenderem as "coisas" pelo tato, é preciso apresentálas de maneira adequada, uma vez que sua apreensão conceitual está circunscrita à área tocada. Mosquera et al. (2015, p. 56) advertem que "Explorações táteis que buscam o reconhecimento de objetos, no caso de indivíduos cegos de nascença, acionam, segundo a teoria da plasticidade cerebral, lobos occipitais, que são os responsáveis pela decodificação das imagens". A plasticidade cerebral permite arranjos neurais incomuns, que ativam regiões do cérebro responsáveis pelo conhecimento e reconhecimento de imagens. Para atender às necessidades de aprendizagem da criança cega congênita, a escola precisa adotar a exploração tátil, envolvendo a cognição, o que precisa ser estimulado, ensinado e aprendido. "Esta relação talvez se processe por meio de um aprender a "pensar tatilmente", assim como se constitui o "pensar visualmente", para os que enxergam" (CARDEAL, 2009, p. 50).

Existem diferenças no desenvolvimento das crianças que nasceram cegas e se constituíram por meio dos seus sentidos preservados, daquelas que perderam a visão, após alguns anos de vida, tendo alguma estrutura já formada pela visão. As crianças que perderam a visão, antes dos cinco anos de idade, são consideradas cegas congênitas, porque possuem pouca ou nenhuma memória visual. É fundamental considerar essas distinções (HATWELL, 2003; AMIRALIAN, 1997). É preciso valorizar um modo de percepção que é háptico, que se constitui por um sistema tátilcinestésico, em que aspectos perceptivos e motores se imbricam para o reconhecimento de objetos.

\footnotetext{
A percepção háptica é uma percepção por fragmentos, aos pedaços, sempre sucessiva e por vezes parciais. Enquanto a visão dá lugar a uma percepção distal e global, o tato fornece um conhecimento por partes e menos estruturado. As sensações sucessivas são aos poucos combinadas e sintetizadas, mobilizando o esforço da atenção e a memória de trabalho. Por sua dimensão cinestésica, a percepção háptica permite conhecer as formas dos objetos, mas também as tensões dos músculos e tendões do corpo. Ao esticar a mão ou levantar um braço, percebemos como o corpo, como um todo, se organiza e se localiza no espaço. São sinais importantes, por exemplo, para um bailarino controlar os movimentos de seu corpo e para uma pessoa cega se deslocar em casa ou na rua (KASTRUP, 2015, p. 72).
}

A percepção háptica consiste na articulação entre o tato e a cinestesia, que não está presente no tato passivo, no qual a informação tátil é recebida de forma não intencional. Nessa perspectiva, 
o que devemos questionar não é a forma como as crianças com deficiência visual percebem o mundo, mas sim, os modos como as imagens são apresentadas a elas.

É urgente que passemos a entender essas crianças, não por um déficit, mas como indivíduos que compreendem o mundo por uma organização de sua percepção sensorial diferente dos videntes. Conforme aponta Plaza (2008, p.56): "[...] se culturalmente o sentido visual é dominante, parece ser o tato o sentido original a partir do qual todos os demais foram diferenciados. Tato e contato confirmam-nos a realidade que vemos."

As crianças com deficiência visual têm as mesmas necessidades afetivas, físicas, intelectuais, sociais e culturais apresentadas por todas as crianças. Porém, têm necessidades educacionais específicas, caminhos e modos particulares de perceber e compreender o real. Elas mantêm suas relações com o ambiente, por meio das informações disponíveis, adaptadas por seus sentidos remanescentes. Por ausência da visão ou por visualizarem de maneira parcial situações observadas, elas obtêm com relação ao mundo à sua volta, informações geralmente inconsistentes, não relacionadas e fragmentadas, visto que seus sentidos intactos não proporcionam, de forma imediata, uma percepção integral e real do todo. Apesar disso, se tiverem a oportunidade de participar, desde cedo, de ambientes organizadores, que possibilitem trocas socioafetivas favoráveis e experiências, que atendam às suas necessidades de aprendizagem, não apresentarão, em relação às demais crianças, prejuízos relevantes em seu desenvolvimento e aprendizado. "As estruturas mentais serão, então, construídas pela própria criança, através de suas possibilidades de intervenção sobre o meio e pela qualidade de solicitação deste", esclarece Bruno (1997, p. 20).

No caso de crianças com deficiência visual, Laplane e Batista (2008, p. 212) afirmam que "[...] será preciso considerar, dentro dos processos gerais comuns a todos os indivíduos que aprendem, as particularidades que singularizam esses processos." Mas, para tanto, é essencial entender a educação como direito de todos. A visão do diferente como alguém fora da norma traz aspectos negativos às práticas educativas e discursivas, que não contribuem para a formação crítica do professor e para a construção de uma sociedade acolhedora.

\section{CONSIDERAÇÕES FINAIS}

Perante o exposto até aqui, nota-se que as crianças cegas e com baixa visão severa, se não estimuladas de modo adequado, terão dificuldades para se relacionar com o meio. "Para combater esse efeito [...] é preciso investir de forma consciente e planejada na organização de um ambiente que promova a interação social e a participação dessas crianças" (LAPLANE; BATISTA, 2008, p. 214). 
Orientada pelo princípio de assegurar a todos uma educação que contemple os aspectos humanos, a educação inclusiva apresenta-se como alternativa para que seja democratizado não somente o acesso à escola, mas também, as condições de aprendizado a todas as crianças, garantindo-lhes participação e permanência o que pressupõe, necessariamente, respeito à diversidade.

A escola só ensina a todas as crianças, quando considera a necessidade de respeitar e observar as singularidades e potencialidades de cada um, em vez de enfatizar as limitações. Por isso, rever conceitos e práticas educativas é necessário. A inclusão pode ser favorecida por estratégias educativas com base em pesquisas. Atentar para isso é imprescindível, porque não é apenas pela simples presença de crianças com deficiência na escola comum que será garantida a sua efetiva inclusão, mas pela estrutura escolar de que dispõe o professor e quais as estratégias utilizadas por ele nesse contexto (MRECH, 2001).

Retomando o escopo desse estudo, propomos uma ampla discussão sobre como possibilitar aos estudantes com deficiência visual dos anos iniciais da Educação Básica, acesso pleno à literatura infantil: palavra e imagem. Nessa direção, destacamos o artigo 68 ${ }^{\circ}$, da $\mathrm{LBI}^{4}$ (BRASIL, 2015, p. 19): "o poder público deve adotar mecanismos de incentivo à produção, à edição, à difusão, à distribuição e à comercialização de livros em formatos acessíveis [...] com vistas a garantir à pessoa com deficiência o direito de acesso à leitura, à informação e à comunicação." O parágrafo $1^{\circ}$ desse artigo aponta que "nos editais de compras de livros [...] o poder público deverá adotar cláusulas de impedimento à participação de editoras que não ofertem sua produção também em formatos acessíveis" (BRASIL, 2015, p. 19). Mas, o que se evidencia, é que, raramente, as editoras cumprem essa demanda e quando empenham algum esforço, nesse sentido, as produções não atendem às necessidades desse público.

Apesar do esforço em produzir versões transcritas no sistema Braille, em tipos ampliados e com imagens pontilhadas, contornos produzidos por pontos em relevo, sendo, atualmente, o recurso mais utilizado para a produção em série no Brasil, ou até mesmo com texturas, ainda assim, as crianças apresentam dificuldades em perceber e compreender as imagens. "Transformar imagens que possuem perspectiva e representam objetos em três dimensões em relevos de pontos acaba limitando a condição de acesso, esforço que deveria garantir a plena acessibilidade metodológica e conceitual", argumenta Nuernberg (2010, p. 135). E ainda: "[...] a simples transcrição para o relevo de uma imagem originalmente concebida para a percepção visual, sem adaptá-la à realidade perceptiva tátil, apenas corrobora a imposição de códigos visuais a quem a eles não têm acesso, em nome de uma inclusão, que, de fato, acaba se tornando ineficaz", acrescenta Cardeal (2009, p. 120).

\footnotetext{
${ }^{4}$ Lei Brasileira de Inclusão.
} 
O desejável é que esses livros tenham uma qualidade multissensorial que assegure à criança leitora, o reconhecimento da imagem, em sua estrutura e na relação das partes com o todo, a partir de pistas táteis, olfativas e sonoras.

O formato acessível ideal de histórias infantis deve conjugar texto escrito em tipos ampliados (fonte Arial Black; corpo 24 - padrão; letras maiúsculas), no sistema Braille e com imagens multissensoriais, ou seja, que revelem, além da importante função da visão como canal sensorial perceptivo, a capacidade do tato, audição, paladar e olfato de apreender o mundo real e imaginário, confirmando com Piccardi (2011): o corpo todo precisa envolver-se no processo de ensino e de aprendizado. Imagens tridimensionais e interativas, com pistas sensoriais, "porque os cegos constroem seus mundos a partir de sequências de impressões (táteis, auditivas, olfativas) e não sendo capazes, como as pessoas com visão, de uma percepção visual simultânea, de conceber uma cena visual instantânea" (SACKS, 1995, p. 87). Desse modo, possibilitando às crianças com deficiência visual mergulharem nos cenários, explorando seus detalhes para experimentarem novos sentimentos tal como seus colegas videntes. Somente, assim, estariam garantidos direitos equânimes de leitura às crianças com deficiência visual.

Por esse motivo, a questão da acessibilidade estética, na Literatura Infantil, precisa ser assumida pela escola e professores, já que coloca em xeque o paradigma da inclusão frente a uma sociedade visocêntrica. Como transformar, informações visuais em informações capazes de serem percebidas e compreendidas pelo tato, audição e olfato?

Essa pesquisa se preocupou em promover a acessibilidade das crianças cegas e com baixa visão à produção literária infantil, por meio de uma formação que conscientize e habilite professores a criarem essas condições de acesso, produzindo livros, artesanalmente, recurso que permite o uso de materiais diversos, tais como, EVA, madeira, argila, ferro, resina, gesso, cortiça, barbante, etc. respeitando os critérios que atendem às demandas desse leitor:

1. Critérios de forma. As figuras que compõem a ilustração devem ser simplificadas, sendo eliminados os detalhes inúteis; devem ser facilmente reconhecíveis, em sua totalidade, de forma autônoma pela criança ou graças à ajuda do adulto; não devem ser sobrepostas, mas alinhadas e com uma distância suficiente; inicialmente (para as crianças em idade pré-escolar) devem manter a visão frontal na representação do esquema corporal e a visão lateral para os animais.

2. Critérios de textura. Devem ser utilizadas texturas e materiais diversificados e agradáveis ao toque, expressivos e significativos do ponto de vista da percepção, respeitando com precisão o critério de atribuição: se for utilizado, por exemplo, o papel crepom para a grama, não é adequado reutilizá-lo para representar um outro elemento.

3. Critérios de espessura. O limite mínimo de percepção da linha de relevo é de $1 / 2$ $\mathrm{mm}$ de altura e $1 / 2 \mathrm{~mm}$ de largura, mas para discriminar facilmente a figura do fundo é adequado utilizar a espessura de pelo menos $1 \mathrm{~mm}$. 
4. Critérios de posição. Os elementos devem ser colocados segundo um critério de ordem espacial que permita ao leitor uma leitura da totalidade da imagem, utilizando as duas mãos abertas; quando necessário, convém representar a linha de terra não apenas para contextualizar melhor os elementos representados, mas sobretudo para facilitar a exploração por parte da criança.

5. Critérios de dimensão. É necessário respeitar a proporção entre as diferentes partes do objeto e entre os diferentes elementos em função da capacidade de exploração da criança. A reprodução dos elementos é feita em conformidade com as duas dimensões, segundo uma visão frontal ou em planta (projeções ortogonais), uma vez que a prospectiva produz significativas deformações do objeto que dificilmente podem ser aproveitadas rapidamente pela mão dos cegos.

6. Critérios de cor. É adequado utilizar cores primárias com forte contraste na escolha das diferentes texturas e dos variados materiais, respeitando a correspondência cromática da realidade, primeiramente para facilitar a discriminação visual das crianças com deficiência visual, para favorecer o compartilhamento com as crianças sem deficiência visual, mas também porque as crianças cegas possuem o direito à informação cromática que caracteriza a realidade (uma textura amarela para o sol, uma verde para a grama, uma cinza para as nuvens, e assim por diante).

7. Critérios de consistência. É fundamental manter uma correspondência exata entre a imagem tátil e a informação escrita em Braille e com caracteres aumentados (PICCARDI, 2011, p. 4-5) (tradução nossa).

Obedecendo a esses critérios, podemos garantir a legibilidade da obra, que forneça à criança uma multiplicidade de sentidos que possam levá-la ao encontro de novos caminhos para se relacionar com o mundo. Tais livros se comprometem com as dinâmicas da percepção, inferência, conhecimento, reconhecimento, aprendizado e memória porque possibilitam experiências sensoriais diversas que permitem à criança com e sem deficiência visual, explorar texturas, cheiros, cores, formas, sons, utilizando todos os seus sentidos e a imaginação, em busca das possíveis significações das histórias. É importante que a criança possua um conhecimento direto dos elementos da história ou que tenha a possibilidade de evocar sua imaginação por analogia. De fato, é inegável o valor da leitura multissensorial de livros que possam ser tocados, manipulados, ouvidos e vistos, o que representa uma fonte significativa de desenvolvimento cognitivo, linguístico, emocional, social e criativo para todas as crianças (PICCARDI, 2011).

O ideal é que, sempre que possível, os livros literários infantis incorporem a ideia do Desenho Universal para a Aprendizagem, a qual permite identificar e fundamentar a pertinência das dimensões a considerar no planejamento da intervenção pedagógica, de modo a assegurar o acesso, a participação e o sucesso de todos os estudantes. Portanto, é fundamental destacar que esses livros podem ser produzidos artesanalmente, pois não constitui ofensa aos direitos autorais, a reprodução de obras literárias, artísticas ou científicas, para uso exclusivo de pessoas com deficiência visual, sempre que a reprodução, sem fins comerciais, seja feita mediante o sistema Braille ou outro procedimento em qualquer suporte para esses destinatários (BRASIL, 1998). 
Só promoveremos a inclusão das crianças com deficiência visual no universo da Literatura Infantil, se respeitarmos suas peculiaridades e necessidades de aprendizagem, permitindo-lhes, como às demais crianças, viajar imaginariamente no mundo de suas histórias.

\section{REFERÊNCIAS}

ABRAMOVICH, Fanny. Literatura infantil - gostosuras e bobices. São Paulo: Scipione, 1997.

AMIRALIAN, Maria Lucia Toledo Moraes. Compreendendo o Cego: uma visão psicanalítica da cegueira por meio de desenhos-estórias. São Paulo: Casa do Psicólogo, 1997.

BENJAMIN, Walter. A tarefa do tradutor. In: Escritos sobre mito e linguagem. São Paulo: editora 34 - Coedição: Duas Cidades. São Paulo, 2013.

BRASIL. Lei $\mathbf{n}^{\circ} \mathbf{9 . 6 1 0}$, de 19 de fevereiro de 1998. Altera, atualiza e consolida a legislação sobre direitos autorais e dá outras providências. Presidência da República, Casa Civil, Subchefia para assuntos jurídicos, Diário Oficial da União, Brasília, Seção 1, p. 3. 20 de fevereiro de 1998. Disponível em: <http://www.planalto.gov.br/ccivil_03/leis/19610.htm> Acesso em: 27. Jan. 2018, 19:35.

BRASIL. Lei n⿳ 13.146, de 6 de julho de 2015. Institui a Lei Brasileira de Inclusão da Pessoa com Deficiência (Estatuto da Pessoa com Deficiência). Brasília: Câmara dos Deputados. Centro de Documentação e Informação, 2015. $40 \quad$ p. Disponível em: <https://www2.camara.leg.br/legin/fed/lei/2015/lei-13146-6-julho-2015-781174-normapl.html>. Acesso em: 27 jan. 2020.

BRUNO, Marilda Moraes Garcia. Deficiência visual - Reflexão sobre a Prática Pedagógica. São Paulo: Laramara, 1997.

CANDIDO, Antônio. O direito à literatura. In: Vários escritos. $5^{\mathrm{a}}$ ed. Rio de Janeiro: Ouro Sobre Azul, 2011.

CARDEAL, Márcia. Ver com as mãos: a ilustração tátil em livros para crianças cegas. Florianópolis, 2009. 140 f. Dissertação (Mestrado em Artes Visuais) - Centro de Artes - CEART, 
Universidade do Estado de Santa Catarina - UDESC, Florianópolis, 2009. Disponível em: <http://tede.udesc.br/bitstream/tede/834/1/marcia.pdf>. Acesso em: 24 fev. 2020.

COELHO, Nelly Novaes. A Literatura Infantil. São Paulo: Moderna, 2000.

CORRÊA, Hércules Tolêdo. Adolescentes leitores: eles ainda existem. In: PAIVA, Aparecida; EVANGELISTA, Aracy Alves Martins; PAULINO, Graça; MACHADO, Maria Zélia Versiani (Orgs). Literatura e letramento: espaços, suportes e interfaces. $\mathbf{O}$ jogo do livro. Belo Horizonte: Autêntica, 2003.

CUNHA, Maria Antonieta Antunes. Literatura infantil: Teoria \& Prática. São Paulo: Ática, 1991.

HATWELL, Yvette. Psychologie Cognitive de la Cécité Précoce. Paris: Dunot, 2003. 213 p.

KASTRUP, Virgínia. A invenção na ponta dos dedos: a reversão da atenção em pessoas com deficiência visual. Psicologia em Revista, Belo Horizonte: PUC-Minas, v. 13, n. 1, p. 69-93, jun. $2007 . \quad$ Disponível em: <http://periodicos.pucminas.br/index.php/psicologiaemrevista/article/view/261>. Acesso em: 15 dez. 2019.

LAJOLO, Marisa; ZILBERMAN, Regina. Literatura infantil: história e histórias. São Paulo: Ática, 1994.

LAPLANE, Adriana Lia Friszman de; BATISTA, Cecilia Guarnieri. Ver, não ver e aprender: a participação de crianças com baixa visão e cegueira na escola. Cad. Cedes, Campinas, v. 28, n. 75, maio/ago, p. 209-227, 2008. Disponível em: < http://www.scielo.br/pdf/ccedes/v28n75/v28n75a05.pdf >. Acesso em: 28 jan. 2020.

LEFFA, Vilson José. Aspectos da leitura. Porto Alegre: Sagra DC Luzzatt, 1996.

MAIA, Gil. O Visível, o Legível e o Invisível. Cadernos de Literatura para a Infância e a Juventude. Malasartes, $\mathrm{n}^{\circ}$ 10, 2002. 
MOSQUERA, Carlos et al. Neurociência cognitiva: deficientes visuais na escola inclusiva. Revista InCantare, Curitiba, PR, UNESPAR, v. 06, n.01, Jan. /Jun. 2015, p. 52-61. Disponível em: $<$ http://periodicos.unespar.edu.br/index.php/incantare/article/view/547>. Acesso em: $10 \mathrm{fev}$. 2020 .

MRECH, Leny Magalhães. O mercado de saber, o real da educação e dos educadores e a escola como possibilidade. Livre-docência. Faculdade de Educação da USP, 2001.

NUERNBERG, Adriano Henrique. Ilustrações táteis bidimensionais em livros infantis: considerações acerca de sua construção no contexto da educação de crianças com deficiência visual. Revista Educação Especial, Santa Maria, v. 23, n. 36, p. 131-144, jan./abr. 2010. Disponível em: $<$ https://periodicos.ufsm.br/educacaoespecial/article/view/1438/834 >. Acesso em 26 mai. 2010 .

SACKS, Oliver. Um Antropólogo em Marte: sete histórias paradoxais. Ver e não ver. São Paulo: Companhia das Letras, 1995.

TODOROV, Tzvetan. A literatura em perigo. Tradução: Caio Meira. Rio de Janeiro: Difel, 2009.

PLAZA, Julio. Tradução Intersemiótica. São Paulo: Perspectiva, 2008.

PICCARDI, Francesca. I libri tattili illustrati nel processo di educazione all'immagine Del bambino con deficit visivo. 2011. Disponível em: < http://libritattili.prociechi.it/approfondimenti/francesca-piccardi/>. Acesso em: 24 fev. 2020.

SOARES, Magda. Letramento: um tema em três gêneros. Belo Horizonte: Autêntica Editora, 2003.

SOARES, Magda. Letramento e alfabetização: as muitas facetas. Revista Brasileira de Educação. São Paulo: Cortez, n. 25, p. 5-17, jan./abr. 2004. Disponível em: < http://www.scielo.br/pdf/rbedu/n25/n25a01.pdf >. Acesso em: 15 dez. 2019.

VYGOTSKY, Lev Semenovitch. A formação Social da Mente. São Paulo: Martins Fontes, 2007. 
VYGOTSKY, Lev Semenovitch. Pensamento e Linguagem. Trad. Jefferson Luiz Camargo. 4. ed. São Paulo: Martins Fontes, 2008.

VYGOTSKY, Lev Semenovitch. E1 niño ciego. Obras Escogidas. Fundamentos de Defectología. Volumen 2 - V de La Coleción Machado Nuevo Aprendizage. Impreso em España, Madrid, 2012.

ZILBERMAN, Regina. A literatura infantil na escola. São Paulo: Global, 2003. 